\title{
The influence of art education on jewelry design
}

\author{
Çimen Bayburtlu ${ }^{1 \mathrm{a}}$, Leyla Ulusman ${ }^{1}$ \\ ${ }^{1}$ Marmara University Göztepe Campus, Istanbul 34730,Turkey
}

\begin{abstract}
Principally, theory and practice should be in harmony. In Jewelry Design Programmes, the knowledge of light, colour and design should be thought on basis of theories and causations besides visuality and practice. The education of design provides the students an independent aspect and encourages researching and questioning when supported by theoretical knowledge as art history, aesthetics, sociology of art, arts policy and analyzation of works of arts. The fundamental thing in art education is an accurate definition of art and a correct specification of coordinates of art education in accordance with this definition. If universal art coordinates are not included in Jewelry Design Education's scope, it is possible to train craftsmen but not artists. It is a recognized truth that if a work of art has gained a universal value and protected it in time, then it is likely to talk about an artist and artistic values. Unique art works have their own creation laws and prove themselves in time.
\end{abstract}

Keywords:art; interdisciplinary art; jewelry; design

\section{Introduction}

Education is the way to universal thinking besides individual improvement and social adaptation. A multi way education concept includes knowledge, experience, existing values and activity. An education orientation that a question, reasons and that solidifies the various rapid technological developments in the light of theoretical knowledge will enrich the vision of the students.

In functional knowledge, "Awareness" is realized after the two qualifications, "Vision and Depth of Vision", are assumed to be assembled. And this awareness revives the fact called philosophical base. Vision is strengthened by the base of knowledge and so the existing creativity reveals itself in the best way.

The peculiar content and form efforts of every designer follows a way from concrete to abstract and then from abstract to concrete. At this point, existence of a rich imagination is a must. Ismail Tunali has expressed Plato's philosophy in current language as: The works of an artist or a craftsman, plastic or literary products, all are formed by the transmission of feelings and ideas to the empirical world of the producer, [6].

\footnotetext{
${ }^{a}$ Corresponding author: cimen.bayburtlu@marmara.edu.tr
} 
Rolla May, by representing his first independent message in his book 'Man's Search for Himself' has established the existentialist approach to creative courage, which is the name of another book of him, [5]. Does meaning have to come after technology? With an existentialist approach this tendency is just the opposite way: Technology comes after meaning. Technology is only efficient if the content has high quality. Form is the element that is dependent to the content and that serves to it. Form alone does not have an artistic value. A form lacking of emotions and ideas would never have an artistic value, [4].

\subsection{Art Education}

In art education, the most important way to improve the technical ability is to give the students knowledge about interdisciplinary interaction. In this respect, it is necessary to enrich the education by basic programs as art history, aesthetics, and sociology of art, arts policy and analyzation of works of arts. In this way; instead of having insignificant object, it is possible to turn the design into works of art that embrace the independent expressions and ideas of the artist, under the influence of this knowledge.

Knowledge of art should be internalized by the students of art and design, especially in art schools and universities. Theoretical knowledge is necessary in design process. Students should have the ability to express themselves and their works and also to ascribe their story and philosophy to the design. S1tkı M. Erinç expresses:"As 'value' is independent to knowledge of an art work occupying a space in its kind, only this 'value' is capable of inserting philosophy into art education.”, [2].

Art is not only technical proficiency as usually understood. Any education improving technical skills does not necessarily improve the art or the artist. It is not possible to call anyone applying art an artist. Because in art, the individuality, the newness and the uniqueness of the work of art is fundamental, not the craftsmanship. Art is a fact that could never be thought without a human being and enables us to recognize ourselves. Sitkı Erinç has expressed that art is the best way to get to know ourselves, in these words: We sense ourselves as how we sense the world, or we sense the world as we sense ourselves. The best way (or the first) to perceive ourselves properly, or in a proper way is art, [3].

A human being is capable of designing new products or new life styles by his creative thinking ability beyond his instincts. History of art and culture is full of related examples. As Ayla Ersor indicates: When the life styles, ideas of people change new essences are born in art and these innovations create new forms. All these changes sometimes easily all of a sudden and sometimes they are built up very slowly with great effort, [4]

\subsection{Design Education}

Art, in the most general saying is the expression process of our emotions and ideas by a practical action using a distinctive language and style.

Design comes out as a result of conscious planning. Both in art and design the principal concept is the "idea". Art and design sometimes interfere with each other and sometimes they come across. Planning in art is different than planning in design. Design brings along a collective work consciousness as art is the independent creation of an individual. Individual thinking does not wonder about the possibility or feasibility of the work.

It is examined what is and what should be art and design by focusing on concrete samples, current and historical references and it has come out that the study of form together with content of art works and designs by referring to the theories underneath has become a necessity in art education. The analyzation of art considering different methods 
and aspects within an intellectual and theoretical context will lead artists to unique design. The process of creating artistic images specifically disassociate from scientific thinking.

The imaginary, supernatural creation that is not perceived by simple eye and that needs deep sensation together with interiority will become deeper by having lessons as art philosophy, art sociology, mythology, art history, arts policy, aesthetics, history of civilization and the works will be much more original and will present themselves much more artistically. Because the process of generating ourselves depending on independent creativity can be realized by the awareness of the individual.2.1.2 Formatting author names and author affiliations

Author names should be typed in 10-point Times. The style for the names is First Names then Last Name, with a comma after all except the last author, which is separated by comma + "and". Do not use academic titles.

Affiliations of authors should be typed in italic 9-point Times. They should be preceded by a numerical superscript corresponding to the same superscript after the name of the author concerned. Please ensure that affiliations are as full and complete as possible and include the country.

\section{Findings}

Students' opinions on the influence of art education and design:

This section is prepared referring to the students' opinions. The answers given to the question what is the efficacy of theoretical lessons as art history, social psychology, art sociology, arts policy, art criticism, and aesthetics is just the expected:

-We evade of becoming craftsman solely by having these art lessons in this kind of schools. We gain the proficiency of being unique in creating distinctive designs by combining arts and crafts.

-The education system intended to the followed improves us in becoming designers aware of their past as have learned world art, human psychology aesthetical point of view and history of jewelry and so able of constituting their future and creating artistic designs from jewelry.

-Theoretical lessons are the nutritional source of applied courses. They open doors to various fields and enriched the thinking.

-Though it is believed that designing is directly proportional to talent, it is actual that education is the most effective factor in design.

-People are gifted with talent by birth. Education is needed in order to improve and support the utilization of this talent properly. It is important to have application and theoretical knowledge well combined. At this point it is necessary to mention Bauhaus School, which has been established in the first half of twentieth century. In this school it was thought when talent is enriched by education, design would gain many distinctive properties.

-Social psychology prepares us for social life. As our knowledge grows we get ready for life and at the point where artistic know-how is built up we begin to think as an artist, have an artistic view and we begin to create.

-Artistic sensation cannot be built up indiscriminately. A conscious process is necessary for the formation of this emotion.

\section{Conclusion}

Students that really are intended to be designers have to start with getting to know themselves. This awareness is only possible with the internalization of conceptual knowledge. For instance creative thinking of art movements should be comprehended as 
well as the visual information. As this knowledge is grasped one by one, it will be possible to reach the universal, starting from the particular through an accurate and pleasant way.

In connection with our study we have determined "letter" as the theme for a project. As the first and second grade students' design could not go further than an envelope (Fig. 1-23-4-5), the third and fourth grade students that begun to build up theoretical base have approached the theme much more creatively.

Aygül Aykut expresses as: The basic thinking processes as sense, perception and design have a special composition in art. Image is a result of both observation and abstraction but it is not a mechanical combination of these two, [1].

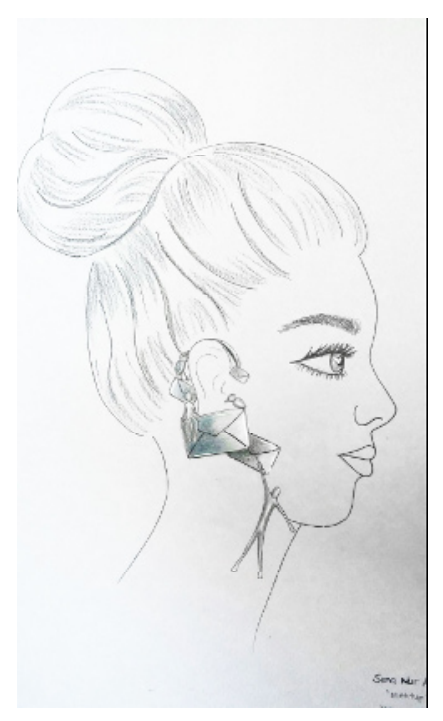

Fig. 1. Second grade, "Letter" themed student design

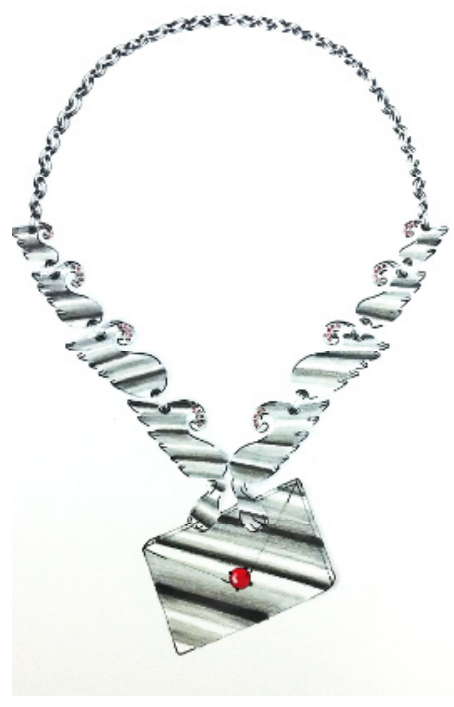

Fig. 2. Second grade, "Letter" themed student design

In Jewelry Design Programmes, the knowledge of light, colour and design should be thought on basis of theories and causations besides visuality and practice. The education of design provides the students an independent aspect and encourages researching and questioning when supported by theoretical knowledge as art history, aesthetics, and sociology of art, arts policy and analyzation of works of arts. Students raised in this spirit create awareness as they can grow their commentations.

Designs and applications of the third and fourth grade students who have taken theoretical lessons are different in both visual and intellectual aspects. 


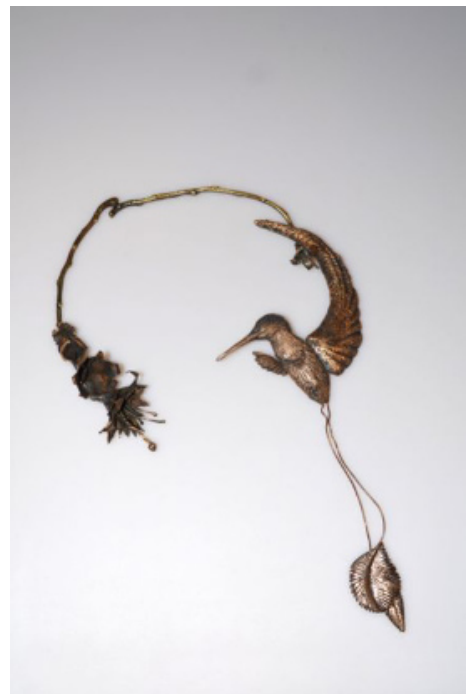

Fig. 3. Third grade, "Letter" themed student designs and applications

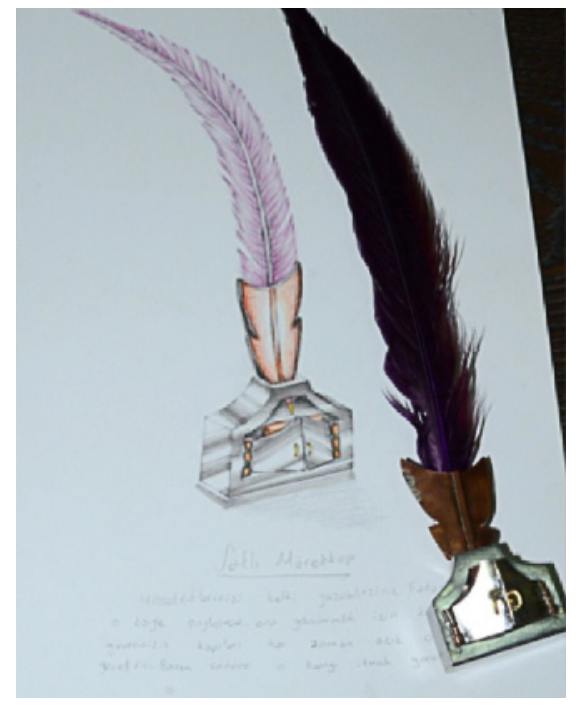

Fig. 4. Third grade, "Letter" themed student designs and applications

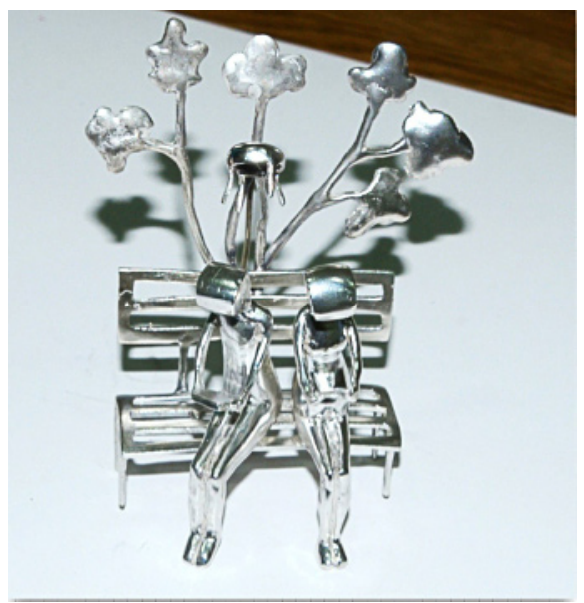

Fig. 5. Third grade, "Letter" themed student designs and applications

And "letter" theme has been described as the dialog of parents with their unborn child. 


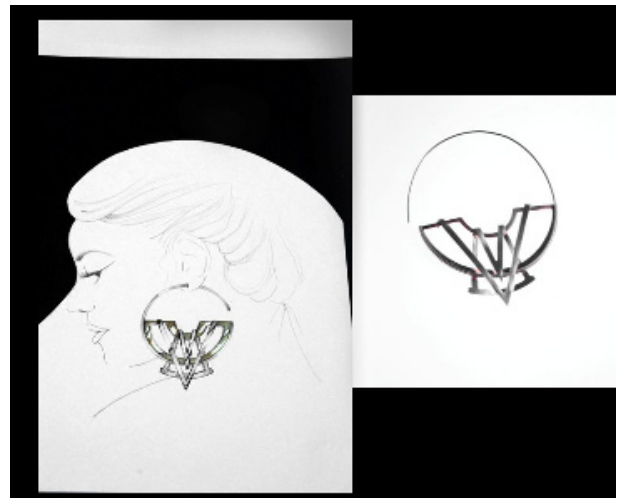

Fig. 6. Fourth grade, "Letter" themed student design and application

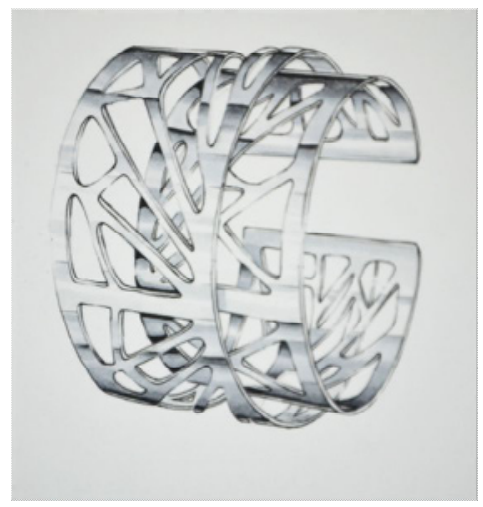

Fig. 8. Fourth grade, "Letter" themed student design and application

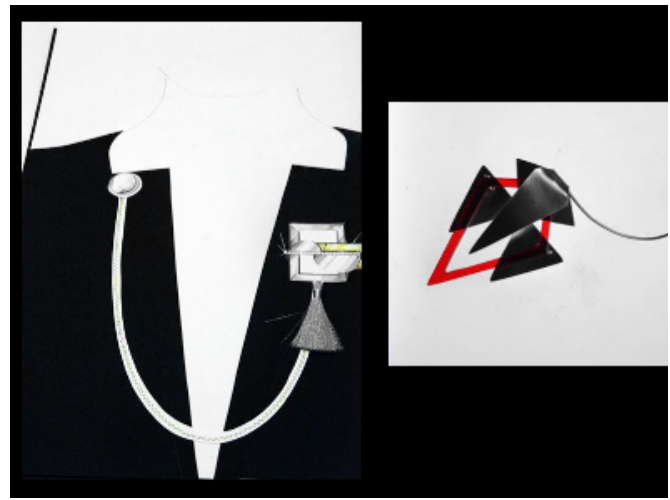

Fig. 7. Fourth grade, "Letter" themed student design and application

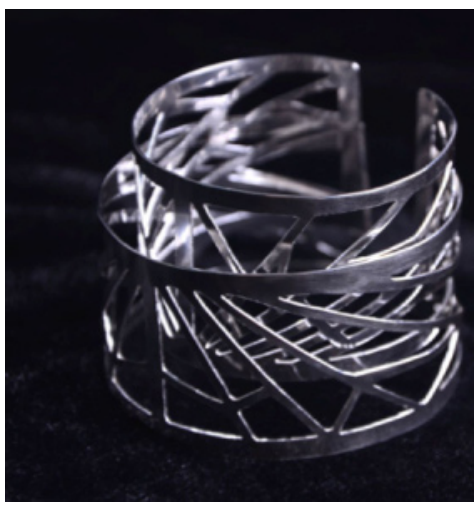

Fig. 9. Fourth grade, "Letter" themed student design and application

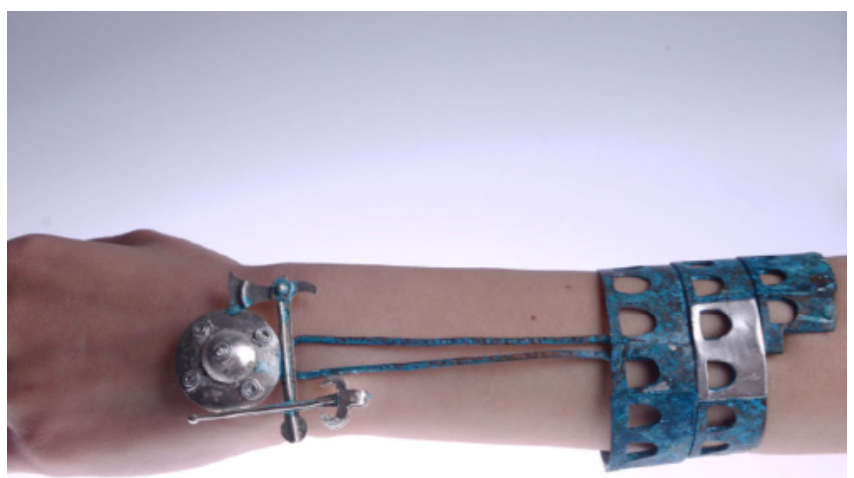

Fig.10. Fourth grade, "Letter" themed student design and application 
"Letter" theme has been identified as the intellectual and historical differences between "west and east".

It has been realized that the designs enriched by theoretical lessons have come out different in many ways and have lead students to their individual awareness.

Removing the boundaries between arts and all branches of art supporting each other with their different expression ways is the fact of our time. Thus different expositions occur and borders are exceeded and so new languages gather with creative identities.

Designing process through individual to common creation has to create its own dynamics. This creation model embraces a collective consciousness and has responsibilities against the art world. Also, the responsibility of the designer against all the humanity should never be forgotten.

The fundamental thing in art education is the right definition of art and the determination of the right coordinates of art education according to this definition. If the education system does not contain universally valid coordinates then we will be raising craftsmen, not artists. Then we may not talk about improvement in design concept.

We may mention a jewellery design as catching the coordinates of art if the work links us up to the designer. There exist the names "Dali" and "Sevan Bıçakçı" in jewellery design because both Dali's and Sevan Bıçakçı's works have protected their values in time with their magnificent glory and they reflect their stories.

In this context, art education must not be regarded as a supplementary, but instead must be approved as a requisite referring to its specific structure.

\section{References}

1. Aykut, A., Sanat eğitiminde estetik (Aesthetic in art education). Hayalperest, 59, (2012).

2. Erinç, S. M., Kültür sanat, sanat kültür (Culture-Art, Art-Culture). Ütopya Yayınevi, 4. Bask1, 109, (2004).

3. Erinç, S. M., Sanat psikolojisine giriş (Introduction to Art Physocology). Ütopya Yayınevi, 3. Baskı, 8, (2011).

4. Ersoy, A., Sanat kavramlarina giriş (Introduction to Art Concepts). Yorum Yayınevi, 3. Bask1, 138., (2002).

5. May, R., Yaratma cesareti (The Courage to create). Metis Yayıncılık, 9. Basım, 11., (2005).

6. Tunalı, I., Tasarım felsefesine giriş (Introduction to design philosopy). Yapı Yayınları, 2. Bask1, 51, (2004). 